\title{
A New Approach for Power-Aware Routing for Mobile Adhoc Networks Using Cluster Head With Gateway Table
}

\author{
Pawan, B. S. Anangpuria Institutue of Technology and Management, India \\ Susheela Hooda, Chitkara University Institute of Engineering and Technology, Chitkara University, India
}

\begin{abstract}
Wireless ad-hoc networks have become the most vibrant and vital area of research over the past years. Most devices in MANET are power operated. Therefore, the need of the hour is to design a protocol that will not only saves the battery life but also increase the lifetime of participating nodes in the ad-hoc network. In this paper, a new power-aware routing protocol has been proposed which selects the best gateway node for sending the data packets from source to destination. Additionally, the proposed routing protocol extends the battery lifetime of a mobile node and also minimizes the power consumption of an entire network. Moreover, this paper also presents an experimental evaluation of the proposed routing protocol by using three parameters (remaining power path, remaining battery power, and hop count) and provide the best path.
\end{abstract}

\section{KEYWORDS}

MANET, Power Consumption, Power-Aware Routing Protocols, Wireless Ad Hoc Networks

\section{INTRODUCTION}

Mobile adhoc networks are commonly known as multi hop wireless networks in which mobile hosts communicate in the network without any centralized access point and infrastructure. Communication between nodes is possible only, when the nodes are located within the radio range of each other. If both communicating nodes are not within the radio range of each other, then messages are to be sent through a hop node. Hop node is nothing but it is simply a mobile node that falls into the overlapping zone of both communicating nodes (sender and receiver node). "It may be noted that due to limited transmission range of wireless network interfaces, multiple network hops may be needed for exchanging the data across the network" (Ad Hoc Networks, n.d.). In MANET, mobile nodes dynamically establish their routes among themselves and form their own network in an adhoc fashion(Toh, 1996). Consequently, such wireless networks have dynamically, rapidly, randomly and multi hop topologies which are composed of relatively bandwidth-constrained like wireless links, limited battery power etc. Therefore, robust and efficient operations have been performed in mobile ad- hoc network (Chen \& Nahrstedt, 1999)(Pathak \& Kumar, 2017). Moreover, quality of service (QoS) is the utmost requirement for MANET applications(Murthy \& Garcia-Luna-Aceves, 1994). Efficient communication and load balancing are an important features for better usage of resources and to increase the quality and performance of the network (Deepa \& Sutha, 2018). 
This paper has been divided into four sections. Section 1 caters a brief description about MANET and section 2 provides a related work. Section 3 presents a proposed protocols and result analysis and section 4 presents conclusion and future work.

\section{RELATED WORK}

Nodes in mobile ad hoc network are power operated and they are located in such an environment where information needs to be relayed from one point to another point in the absence of a base station. Sometimes, it is impossible to charge the batteries of remotely located nodes. Therefore, power saving nodes are to be needed to increase the lifetime of the network.

Due to availability of less number of resources and power capacity, maintaining an ad-hoc network becomes a significant technical challenge before the researchers(Hannan et al., 2000) (Sharma et al., 2015). Moreover, these characterstic impose restrictions on the network in terms of connectivity of nodes and efficiency of packet transmission. Numerous researchers have been focusing on designing various routing protocols those extend the lifetime of a mobile node and minimize the power consumption of entire network(Wu \& Harms, 2001)(Perkins \& Hughes, 2002)(Punde et al., 2003)(Johnson \& Maltz, 1996)(Sharma \& Goel, 2005)(Pathak \& Kumar, 2017). In the existing power routing protocols, the maximum number of nodes participate for packet transmission from source node to destination node and minimum number of nodes remain in idle mode. These algorithms and schemes are collectively known as 'power-aware routing' protocols. Some of the power-aware existing routing protocols have been described below:

Power-aware source routing (PSR) is one of the power aware routing protocol which is based on dynamic source routing (DSR) protocol(Sharma et al., 2015). It balances the traffic load inside the network. This protocol tries to balance the load in the network.Therefore, it may choose the path, whose power consumption may be high. Moreover, PSR uses DSR, therefore, there will be time wastage in forming the route.

Minimum Total Power Protocol (MTPR) is another power routing protocol which selects the next node on the basis of shortest path between its neighboring nodes. The neighbor node is the node which is selected to be the next node. Thus, the total transmission power consumption is minimized for sending the data packet from source node to destination node (Johnson \& Maltz, 1996). Therefore, maximum numbers of nodes participate for data transmission in MTPR.It always selects its nearest neighbor node. Therefore, it leads to network congestion problem.

Minimum Battery Cost Routing (MBCR) is another power routing protocol which selects the next node on the basis of battery cost. This protocol, firstly, find the total battery cost for each route from source to destination and then selects the route for transmission which has the minimum total cost among all routes(Xue \& Ganz, 2003).

Sivakumar et.al. proposed a protocol which selects the route with shorter hop count if all the nodes have same battery capacity(Wu \& Harms, 2001). However, since it is the summation that must be minimal, some hosts may be overused because a route containing nodes with little remaining battery capacity may still be selected (Deepa \& Sutha, 2018). Therefore, power consumption is more due to maximum number of nodes participate for data transmission.

A critical look at available literature indicates that the following issues need to be addressed while designing a power aware routing protocol such as:

1. The existing Power Aware Routing Protocols use large number of hop nodes for packet transmission from source node to destination node.

2. The number of packets exchanged is very large.

3. The existing power aware routing protocols broadcast packets resulting in packet flooding.

4. The overall power consumption is very high. 
In this paper, a cluster head based power routing protocol has been designed that addresses the above highlighted issues. A gateway table has also been introduced that significantly reduces the hop count of the route from source to destination node. The main objective of the paper is to design a protocol that extend the battery lifetime of a mobile node and also minimizes the power consumption of entire network. In the existing power aware routing protocols the maximum number of nodes participate for packet transmission from source node to destination node. Therefore, they consume maximum battery power.

The main objectives of the proposed power aware routing protocol are:

1. To reduce the power consumption

2. To reduce the number of nodes used in data transfer from source to destination node.

3. To provide an optimized path for packets transmission from source to destination node.

4. To choose a gateway for routing in an intelligent manner.

\section{PROPOSED ROUTING PROTOCOL}

This section describes the proposed routing algorithm which selects the best transmission path from source node to destination node which consumes least power. The nodes belonging to the same cells, formed a cluster. One of the node from the cell which has maximum battery power is designated as a cluster head $(\mathrm{CH})$. Various nodes of the cell can directly communicate with the Cluster Head $(\mathrm{CH})$ (Punde et al., 2003).

\section{Figure 1. An Adhoc Network of two cells}

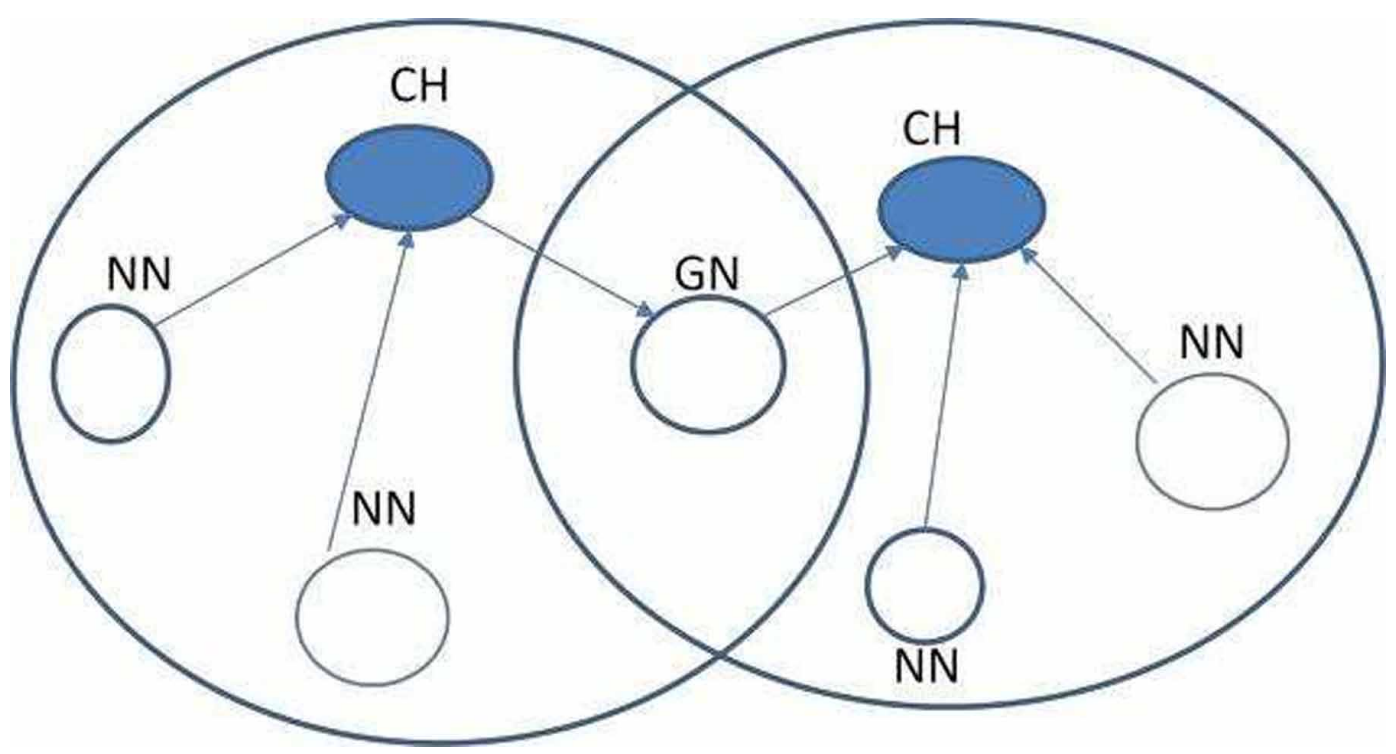

In the above fig.1, Cluster Head (CH) classifies the nodes into two categories:- 1) Normal Node (NN) and, 2) Gateway Node(GN). Normal Node (NN) belongs to the same cell. A GN is also the node that belongs to the same cluster but it is also member of some other adjacent cell(s) (Sharma \& Goel, 2005)(Sharma et al., 2015). Each Normal Node (NN) maintains a table called, 'Neighbor Awareness List (NAL)' for storing the information about its immediate neighboring nodes present 
within the cell. The Neighbor Awareness List contains the IP-Address of the neighboring node in the increasing order of power signal of the corresponding nodes. The format of NAL has been shown

Table 1. Neighbor Awareness List(NAL)

\begin{tabular}{|c|c|c|c|c|c|}
\hline Node- Id & IP-Address & $\begin{array}{c}\text { Remaining } \\
\text { Battery Power }\end{array}$ & Node Types & Idle Time & $\begin{array}{c}\text { Token } \\
\text { Number }\end{array}$ \\
\hline
\end{tabular}

in below table 1 .

Where,

Node-Id: A Unique number assigned to the nodes

IP-Address: contains the IP address of the existing node of a cell

Node Type: 0, 1 indicating the normal node, cluster node respectively

Remaining Battery Power: Defines the remaining battery power of a node . Value of battery power is assumed between $0-100$.

Idle Time: The amount of time for which the node has not participated in packet transfer activity.

Token Number: Every node is assigned a token at the time of its joining the cluster. The token number represents that as for how long a node has been presented in the cell.Value of token number is assumed between $0-200$.

\section{Methodology of Proposed Routing Protocol}

This section describes the methodology for the proposed power aware routing protocol. The following steps has to be taken:-

1. First, the source node checks the destination node in its own cell, if destination node is not found in its own cell then it sends BR packet (see table 2) to its ' $\mathrm{CH}$ '. When a node enters a cell, it broadcasts a Beacon Request Packet called 'BR' to convey its arrival in the cell to other nodes. On receiving the packet broadcasted by the new entrant, the each recipient node loads the details about new entrant into its own NAL and NAT. Thereafter the recipient node acknowledges the receipt of the BR by sending a (Beacon Reply Packet) called 'BP' (see table 3) with packet type equal to 1 .

2. Then, $\mathrm{CH}$ sends the BR packet to all the GN present in the current cell. After receiving the BR packet from $\mathrm{CH}$, a GN node checks the destination node in its own NAL and if not found then it sends the packet to $\mathrm{CH}$ of the adjacent cell and so on. If destination node is found in the NAT table (see Table 4) of the recipient $\mathrm{CH}$ of adjacent cell then the $\mathrm{CH}$ sends back a BP packet to the $\mathrm{CH}$ of the immediate previous cell with hop count set equal to one and rempowpath equal to its remaining battery.

3. In the return journey the BP packet traces its path back to the source node and every intermediate node increments the Hop Count by 1 and adds its remaining battery power to the variable called rempowpath contained in of the BP (see Table 3) packet before forwarding it back to previous $\mathrm{CH}$.

4. A BP packet contains an information about path length in terms of Hop Count and remaining battery power of path from source node to destination node.

5. After receiving BP packet by source node, it computes the Average power of the path by the following formula. 
It may be noted that the value of remPowPath is taken from the Gateway Table. The format of Gateway Table has been shown in Table 5.

If the $\mathrm{BP}$ is received from more than one path then it sends the packets to the GN node that leads to path with maximum average power.

The formatof BR Packet is given in Table 2.

Where,

Packet Type 0: Indicates that it is a request packets

Source Address: contains the IP address of sender Node

Destination Node: contains the broadcast IP address

Table 2. Beacon Request Packet(BR)

\begin{tabular}{|c|c|c|c|c|}
\hline $\begin{array}{c}\text { Packet Types } \\
\text { 0 }\end{array}$ & $\begin{array}{c}\text { Remaining Battery } \\
\text { Power } \\
\text { (BRP) }\end{array}$ & $\begin{array}{c}\text { Source } \\
\text { Address }\end{array}$ & $\begin{array}{c}\text { Destination } \\
\text { Node }\end{array}$ & $\begin{array}{c}\text { Hop } \\
\text { Count }\end{array}$ \\
\hline
\end{tabular}

Remaining Battery Power: value of battery power assumed to vary between 0-100

Hop Count:Path length from source to destination node

The format of BP Packet is given in Table 3.

Where,

Packet Type: 1 indicating that it is a reply packet

Source Address: contain the IP address of receiver node

Destination node: contain the IP address of the node that has sent a BR packets

Table 3. Beacon Reply Packet (BP)

\begin{tabular}{|c|c|c|c|c|c|c|c|}
\hline $\begin{array}{c}\text { Packet } \\
\text { type }\end{array}$ & $\begin{array}{c}\text { Source } \\
\text { address }\end{array}$ & $\begin{array}{c}\text { Destination } \\
\text { address }\end{array}$ & Node type & Idle time & $\begin{array}{c}\text { Token } \\
\text { number }\end{array}$ & Hop count & $\begin{array}{c}\text { Rempowpath } \\
\text { (RPP) }\end{array}$ \\
\hline
\end{tabular}

Node Type: $0,1,2$ indicating the normal node, cluster node and gateway node respectively

Idle Time: Idle time of a node

Token number: Value of token number assumed to vary between 0-20

Hop count:Path length from source to destination node

Rempowpath: represents the sum of remaining battery power of intermediate nodes from source to destination

The format of Neighbor Awareness Table (NAT) is given in Table 4.

Where,

Neighbor: contain the list of neighbor nodes within the cell of the cluster head

Remaining Battery Power: value of battery assumed to vary between 0-100N

Node Type: $0,1,2$ indicating the normal node, gateway node and cluster node respectively 
Table 4. Neighbor Awareness Table (NAT)

\begin{tabular}{|l|c|l|l|l|l|l|}
\hline Neighbor & $\begin{array}{c}\text { Remaining } \\
\text { Battery } \\
\text { Power }\end{array}$ & $\begin{array}{c}\text { Node } \\
\text { type }\end{array}$ & $\begin{array}{c}\text { Remote } \\
\text { Neighbor }\end{array}$ & $\begin{array}{c}\text { Idle } \\
\text { Time }\end{array}$ & $\begin{array}{c}\text { Token } \\
\text { Number }\end{array}$ \\
\hline
\end{tabular}

Idle Time: Idle time of a node

Token Number: Value of token number is assumed between 0-200.

The format of Gateway Table is given in Table 5.

Where

Nodes: Unique id of nodes

Remaining Battery Power: value of battery power assumed to vary between 0-100

remPowPath: Remaining power of node along with sum of power of adjacent node

Table 5. Gateway Table

\begin{tabular}{|c|c|c|}
\hline Node & Remaining Battery Power(RBP) & remPowPath of Path1 \\
\hline
\end{tabular}

\section{Experimental Evaluation of the Proposed Routing Protocol}

This section describes the experimental evaluation of the proposed power aware routing protocol. The proposed power aware routing protocol has been applied on the scenario given in Figure 2.

In the above Figure 2, there are 19 nodes of different types $(\mathrm{GN}, \mathrm{CH}, \mathrm{NN})$ and these are represented in six cells. The detail description of each node of fig. 2 has been given in table 6 .

Let us assume that node 2 and node 19 are source and destination nodes respectively. The proposed power aware routing protocol works as follow:

1. Node 2 checks the destination node in its own cell, if the destination node is not found in its own cell then it sends the packet to its cluster head ' $\mathrm{CH}$ '.

2. Thereafter, $\mathrm{CH}$ sends the BR packets to all its GN nodes i.e. 4 and 3 respectively of the its cell.

BR packet of gateway node 4 and 3 is given below in Table 7 .

3. After Receiving the BR packet fromCH,the GN Nodes 3 and 4 consult their own NAL for the destination node. If destination node is not found in the respective NAL of a GN then packet is sent to $\mathrm{CH}$ of adjacent cell for instance $\mathrm{GN}(4)$ sends the packet to $\mathrm{CH}(8)$ and $\mathrm{GN}(3)$ sends the packet to $\mathrm{CH}(7)$ as shown in Fig.2.

4. If destination node is found in the NAT table of $\mathrm{CH}$ of adjacent cell then $\mathrm{CH}$ returns the BP packet to $\mathrm{CH}$ of immediate previous cell the with updated hop count value and rempowpath(see Table 9).

As soon as the destination node is found, the $\mathrm{CH}$ of the respective cell sendsthe BP packet back to the source node.

The contents of Beacon Reply Packet (BP) as received by GN node 4 is given in Table 14 . 
Figure 2. Adhoc Network of six cells

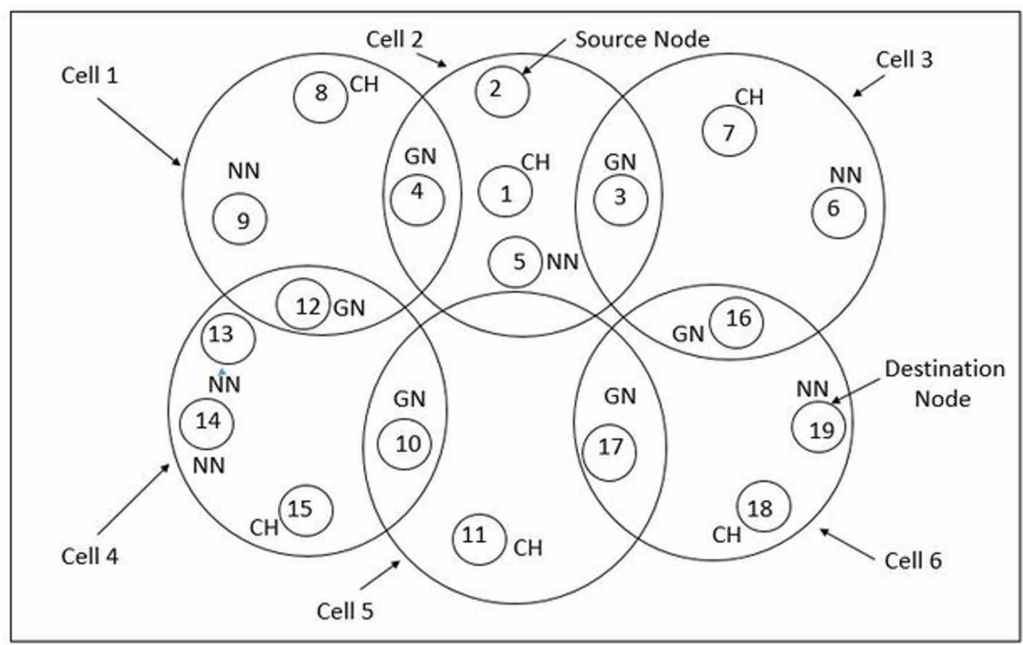

Table 6. Detail of nodes

\begin{tabular}{|c|c|}
\hline Cell & Nodes \\
\hline 1 & $4,8,9,12$ \\
\hline 2 & $1,2,3,4,5$ \\
\hline 3 & $3,6,7,16$ \\
\hline 4 & $10,12,13,14,15$ \\
\hline 5 & $10,11,17$ \\
\hline 6 & $16,17,18,19$ \\
\hline
\end{tabular}

Table 7. Beacon Request Packet(BR)

\begin{tabular}{|c|c|c|c|c|}
\hline Packet Types & $\begin{array}{c}\text { Remaining Battery } \\
\text { Power } \\
\text { (BRP) }\end{array}$ & Source Address & Destination Node & $\begin{array}{c}\text { Hop } \\
\text { Count }\end{array}$ \\
\hline 0 & 90 & 2 & 19 & 1 \\
\hline
\end{tabular}

Table 8. Neighbor Awareness Table(NAT) of CH1

\begin{tabular}{|c|c|c|c|c|c|}
\hline Neighbor & $\begin{array}{c}\text { Remaining } \\
\text { Battery } \\
\text { Power }\end{array}$ & $\begin{array}{c}\text { Node } \\
\text { type }\end{array}$ & $\begin{array}{c}\text { Remote } \\
\text { Neighbor }\end{array}$ & $\begin{array}{c}\text { Idle } \\
\text { Time }\end{array}$ & $\begin{array}{c}\text { Token } \\
\text { Number }\end{array}$ \\
\hline 2 & 73 & 0 & Nil & 10 & 5 \\
3 & 83 & 2 & $6,7,16$ & 15 & 7 \\
4 & 7 & 2 & $8,9,12$ & 13 & 8 \\
5 & 9 & 0 & Nil & 11 & 10 \\
\hline
\end{tabular}


The contents of Beacon Reply Packet (BP) as received by GN node 3 is given in Table 15 .

It may noted that the Source node 2 received two BP packets one each from GN(4) and GN(3). Let us suppose Path 1 is the path through GN(4) and Path2 is the path through GN(3)as per the following detailed paths.

Path 1 is: Node19-Node17-Node11-Node10-Node15-Node12-Node8-Node4-Node1-Node2

Above Figure 3 represents the path1 Node19-Node17-Node11-Node10-Node15-Node12-Node8Node4-Node1-Node2 with Hop Count (HC) value.

Path 2 is: Node19-Node16-Node7-Node3-Node1-Node2

Above Figure 4 represents the path1 Node19-Node16-Node7-Node3-Node1-Node2 with Hop Count (HC) value.

The detail of Remaining Battery Power and Rempowpathof nodes of Path1 and Path2 is given in Table 16

Thereafter, the sender node computes the Average power of the each path is given below.

Average power of Path $1=$ Rempowpath / Hop count

$$
=826 / 09
$$

$=91.77$

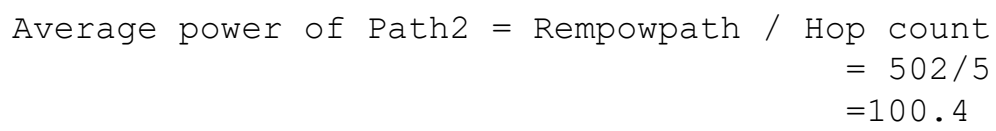

Since the average power of path 2 is maximum than average power of path1. Packet is sent through GN(3)

\section{CONCLUSION}

The proposed power aware routing protocol selects the best gateway node that leads to path with maximum average power. It sends the data packet to that node where the probability to get destination is maximum. Moreover, in the proposed routing protocol, the minimum number of nodes participate for packet transmission from source node to destination node and maximum number of nodes remain in an idle mode. Thus, the proposed routing protocol saves the power consumption by involving minimum number of nodes during data transmission. Thus, a significant contribution has been made towards the design and development of efficient, adaptable, scalable and power saving power routing protocol in the field of MANET. The work reported can be extended in future for big networks.

\section{REFERENCES}

Ad Hoc Networks. (n.d.). Available at: www.adhocnetworks.cfm.htm

Chen, S., \& Nahrstedt, K. (1999). Power Aware Routing in Ad Hoc Networks. IEEE Journal on Selected Areas in Communication, 17(8).

Deepa, J., \& Sutha, J. (2018). A new energy based power aware routing method for MANETs. The Journal of Networks, Software Tools and Applications, 1-8. 
Table 9. Neighbor Awareness Table(NAT) of CH8

\begin{tabular}{|c|c|c|c|c|c|}
\hline Neighbor & $\begin{array}{c}\text { Remaining } \\
\text { Battery } \\
\text { Power }\end{array}$ & $\begin{array}{c}\text { Node } \\
\text { type }\end{array}$ & $\begin{array}{c}\text { Remote } \\
\text { Neighbor }\end{array}$ & $\begin{array}{c}\text { Idle } \\
\text { Time }\end{array}$ & $\begin{array}{c}\text { Token } \\
\text { Number }\end{array}$ \\
\hline 4 & 79 & 2 & $2,3,1,5$ & 10 & 15 \\
9 & 85 & 0 & Nil & 15 & 17 \\
12 & 73 & 2 & $10,13,14,15$ & 13 & 18 \\
\hline
\end{tabular}

Table 10. Neighbor Awareness Table(NAT) of $\mathrm{CH} 7$

\begin{tabular}{|c|c|c|c|c|c|}
\hline Neighbor & $\begin{array}{c}\text { Remaining } \\
\text { Battery } \\
\text { Power }\end{array}$ & $\begin{array}{c}\text { Node } \\
\text { type }\end{array}$ & $\begin{array}{c}\text { Remote } \\
\text { Neighbor }\end{array}$ & $\begin{array}{c}\text { Idle } \\
\text { Time }\end{array}$ & $\begin{array}{c}\text { Token } \\
\text { Number }\end{array}$ \\
\hline 3 & 83 & 2 & $1,2,4,5$ & 11 & 20 \\
6 & 85 & 0 & Nil & 18 & 25 \\
16 & 83 & 2 & $17,18,19$ & 14 & 35 \\
\hline
\end{tabular}

Table 11. Neighbor Awareness Table(NAT) of $\mathrm{CH} 11$

\begin{tabular}{|c|c|c|c|c|c|}
\hline Neighbor & $\begin{array}{c}\text { Remaining } \\
\text { Battery } \\
\text { Power }\end{array}$ & $\begin{array}{c}\text { Node } \\
\text { type }\end{array}$ & $\begin{array}{c}\text { Remote } \\
\text { Neighbor }\end{array}$ & $\begin{array}{c}\text { Idle } \\
\text { Time }\end{array}$ & $\begin{array}{c}\text { Token } \\
\text { Number }\end{array}$ \\
\hline 10 & 83 & 2 & $12,13,14,15$ & 16 & 27 \\
17 & 79 & 2 & $16,18,19$ & 13 & 31 \\
\hline
\end{tabular}

Table 12. Neighbor Awareness Table(NAT) of $\mathrm{CH} 18$

\begin{tabular}{|c|c|c|c|c|c|}
\hline Neighbor & $\begin{array}{c}\text { Remaining } \\
\text { Battery } \\
\text { Power }\end{array}$ & $\begin{array}{c}\text { Node } \\
\text { type }\end{array}$ & $\begin{array}{c}\text { Remote } \\
\text { Neighbor }\end{array}$ & $\begin{array}{c}\text { Idle } \\
\text { Time }\end{array}$ & $\begin{array}{c}\text { Token } \\
\text { Number }\end{array}$ \\
\hline 16 & 83 & 2 & $3,6,7$ & 13 & 27 \\
17 & 79 & 2 & $5,10,11$ & 12 & 24 \\
19 & 85 & 0 & Nil & 13 & 33 \\
\hline
\end{tabular}

Table 13. Neighbor Awareness Table(NAT) of $\mathrm{CH} 15$

\begin{tabular}{|c|c|c|c|c|c|}
\hline Neighbor & $\begin{array}{c}\text { Remaining } \\
\text { Battery } \\
\text { Power }\end{array}$ & $\begin{array}{c}\text { Node } \\
\text { type }\end{array}$ & $\begin{array}{c}\text { Remote } \\
\text { Neighbor }\end{array}$ & $\begin{array}{c}\text { Idle } \\
\text { Time }\end{array}$ & $\begin{array}{c}\text { Token } \\
\text { Number }\end{array}$ \\
\hline 10 & 83 & 2 & $5,11,17$ & 11 & 22 \\
12 & 73 & 2 & $4,8,9$ & 10 & 21 \\
13 & 85 & 0 & Nil & 15 & 19 \\
14 & 86 & 0 & Nil & 17 & 16 \\
\hline
\end{tabular}


International Journal of Web-Based Learning and Teaching Technologies

Volume 16 •Issue 4 • July-August 2021

Table 14. Beacon Reply Packet (BP) as routed through GN(4)

\begin{tabular}{|c|c|c|c|c|c|c|c|}
\hline $\begin{array}{c}\text { Packet } \\
\text { type }\end{array}$ & $\begin{array}{c}\text { Source } \\
\text { address }\end{array}$ & $\begin{array}{c}\text { Destination } \\
\text { Address }\end{array}$ & $\begin{array}{c}\text { Node } \\
\text { Type }\end{array}$ & $\begin{array}{c}\text { Idle } \\
\text { time }\end{array}$ & $\begin{array}{c}\text { Token } \\
\text { Number }\end{array}$ & $\begin{array}{c}\text { Hop } \\
\text { Count }\end{array}$ & Rempowpath(RPP) \\
\hline 1 & 1 & 14 & 2 & 15 & 15 & 9 & 826 \\
\hline
\end{tabular}

Table 15 .Beacon Reply Packet (BP) as routed through GN(3)

\begin{tabular}{|c|c|c|c|c|c|c|c|}
\hline $\begin{array}{c}\text { Packet } \\
\text { type }\end{array}$ & $\begin{array}{c}\text { Source } \\
\text { address }\end{array}$ & $\begin{array}{c}\text { Destination } \\
\text { Address }\end{array}$ & $\begin{array}{c}\text { Node } \\
\text { Type }\end{array}$ & $\begin{array}{c}\text { Idle } \\
\text { time }\end{array}$ & $\begin{array}{c}\text { Token } \\
\text { Number }\end{array}$ & $\begin{array}{c}\text { Hop } \\
\text { Count }\end{array}$ & Rempowpath(RPP) \\
\hline 1 & 1 & 14 & 2 & 15 & 20 & 5 & 502 \\
\hline
\end{tabular}

Figure 3. Path1 with HOP count Value

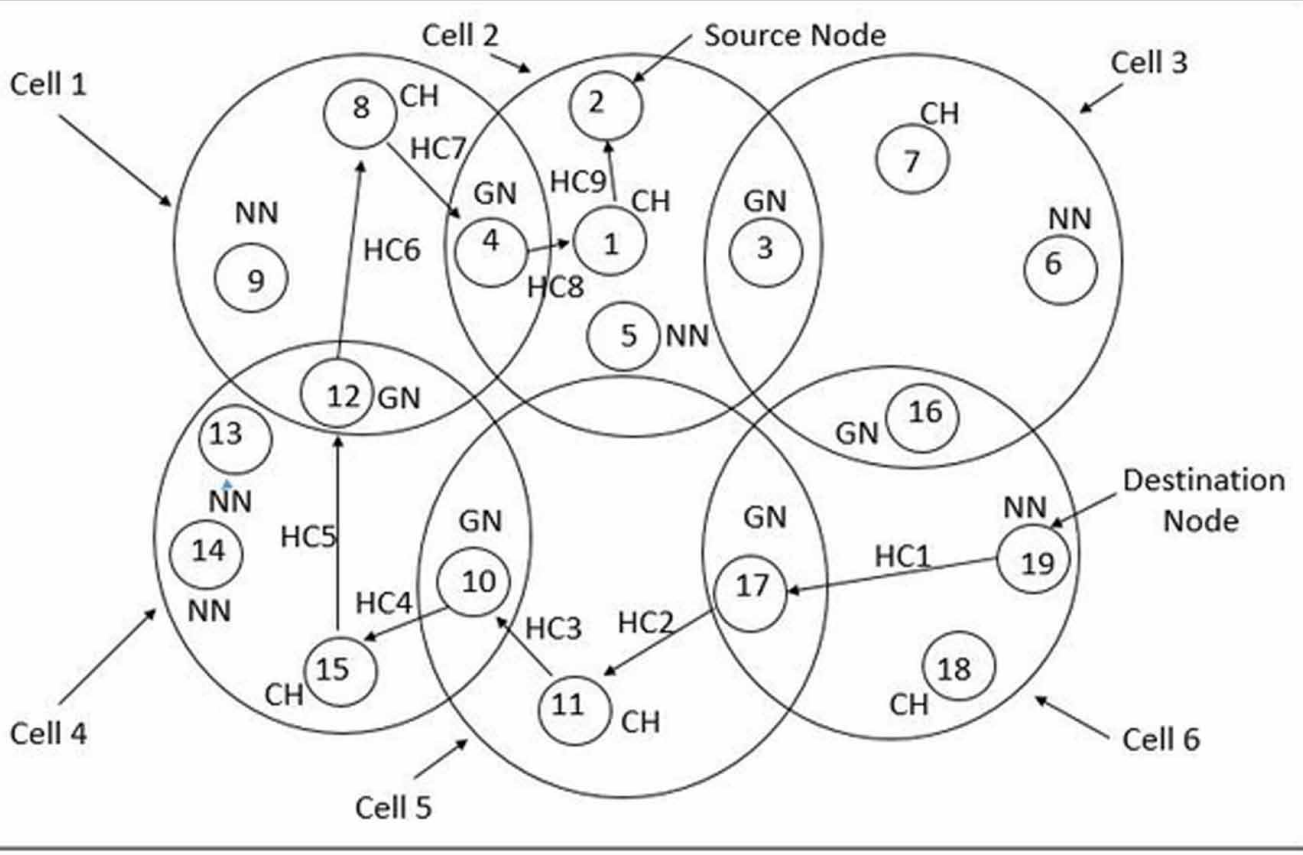


Figure 4. Path2 with HOP count Value

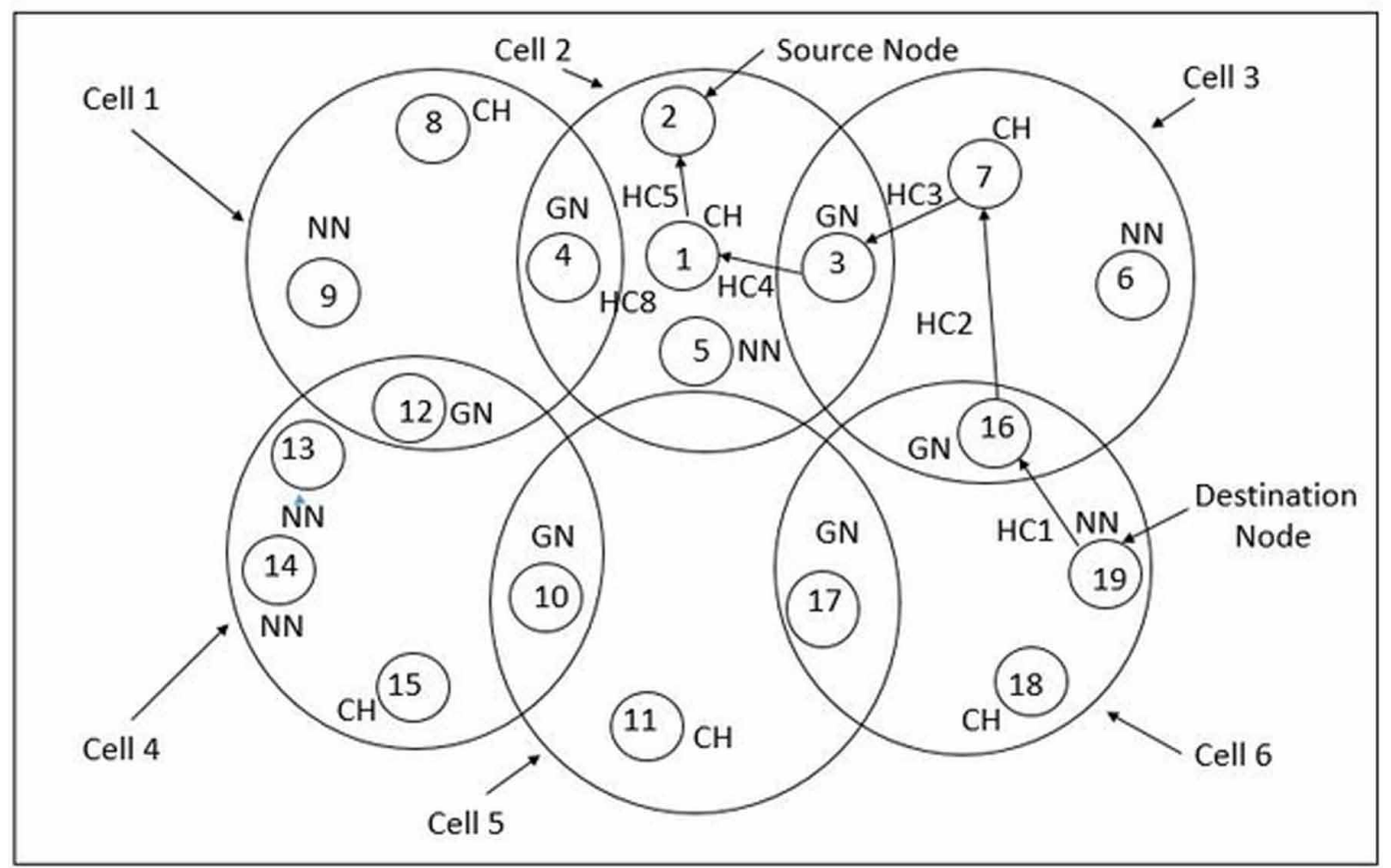


International Journal of Web-Based Learning and Teaching Technologies

Volume $16 \cdot$ Issue $4 \cdot$ July-August 2021

Table 16. BRP and RPP of Path 1 and Path2

\begin{tabular}{|c|c|c|c|}
\hline Nodes & $\begin{array}{c}\text { RemainingBattery Power } \\
\text { (BRP) }\end{array}$ & $\begin{array}{c}\text { Rempowpath of Path1 } \\
\text { (RPP) }\end{array}$ & $\begin{array}{c}\text { Rempowpath of Path2 } \\
\text { (RPP) }\end{array}$ \\
\hline 1 & 90 & 753 & 429 \\
\hline 2 & 73 & 826 & 502 \\
\hline 3 & 83 & ------ & 339 \\
\hline 4 & 79 & 663 & ------ \\
\hline 5 & 85 & ------- & ------ \\
\hline 6 & 85 & ------ & ------ \\
\hline 7 & 88 & ------ & 256 \\
\hline 8 & 89 & 584 & ------ \\
\hline 9 & 85 & ----- & ------- \\
\hline 10 & 83 & 332 & ------- \\
\hline 11 & 85 & 249 & ------- \\
\hline 12 & 73 & 495 & -.-- \\
\hline 13 & 85 & ------ & ------ \\
\hline 14 & 86 & ------ & ------ \\
\hline 15 & 90 & 422 & ----- \\
\hline 16 & 83 & ------- & 168 \\
\hline 17 & 79 & 164 & ------- \\
\hline 18 & 92 & ------- & ------ \\
\hline 19 & 85 & 85 & 85 \\
\hline
\end{tabular}


Hannan, X., Winston, K. G. S., Anthony, L. O., \& Kee Chiang, C. (2000). Flexible Quality Service Model for AdHOC Network. Proceedings of the IEEE Vehicular Technology Conference. doi:10.1109/VETECS.2000.851496

Johnson, D. B., \& Maltz, D. A. (1996). Minimum Battery Cost Routing in Ad-Hoc. Wireless Networks, 213-245.

Murthy, , \& Garcia-Luna-Aceves, . (1994). An Efficient Power Aware Routing Protocol for Network Mobile Computing. Kluwer Academic Publishers.

Pathak, G., \& Kumar, K. (2017). Traffic aware load balancing in AOMDV for mobile Ad-hoc network. Journal of Communications and Information Networks, 2(2), 123-130.

Perkins, D. D., \& Hughes, H. D. (2002). On Line Power Routing Protocol in Mobile Ad-Hoc Networks. Wireless Communications and Mobile Computing.

Punde, J., Pissinou, N., \& Makki, K. (2003). Power Aware Localised Routing in Ad-Hoc Networks. Proceedings of the 28th Annual IEEE International Conference on Local Computer Networks.

Sharma, A. K., \& Goel, A. (2005). Moment to Moment Node Transition Awareness Protocol (MOMENTAP). International Journal of Computer Applications, 1.

Sharma, A.K., Sharma, R.K., \& Pawan, . (2015). A Power Efficient Cluster Head Based Routing Protocol for Mobile Ad-hoc Network. International Journal of Computing Academic Research, 4(3), 119-131.

Sivakumar, R., Sinha, P., \& Bharghavan, V. (1999). CEDAR: A Core Extraction Distributed AdHoc Routing Algorithm. IEEE JSAC, 3(8).

Toh, C. K. (1996). Minimum Total Power Routing in Ad-Hoc Mobile Computing. Proceedings of the 1996 IEEE Fifteenth Annual International Phoenix Conference on Computers and Communication, 480-486.

Wu, K., \& Harms, J. (2001). Power Aware Source Routing in MANET. Academic Press.

Xue, Q., \& Ganz, A. (2003). Wireless Routing Protocol in Mobile Ad Hoc Networks. Journal of Parallel and Distributed Computing, 63, 154-165. doi:10.1016/S0743-7315(02)00061-8

Pawan Kumar is working as a Professor and Head of the Department in B.S. Anangpuria Institute of Technology and Management. He has more than 15 years of experience in teaching and research. His area of interest is Mobile Ad-hoc Network, Cloud Computing, Machine Learning, etc.

Susheela Hooda is working as an Assistant Professor at Chitkara University Institute of Engineering and Technology, Chitkara University, Punjab, India. She has more than 12 years of teaching and research experience in various fields (MANET, Cloud Computing, Software Testing, Big Data Analytics, Data Mining). 